
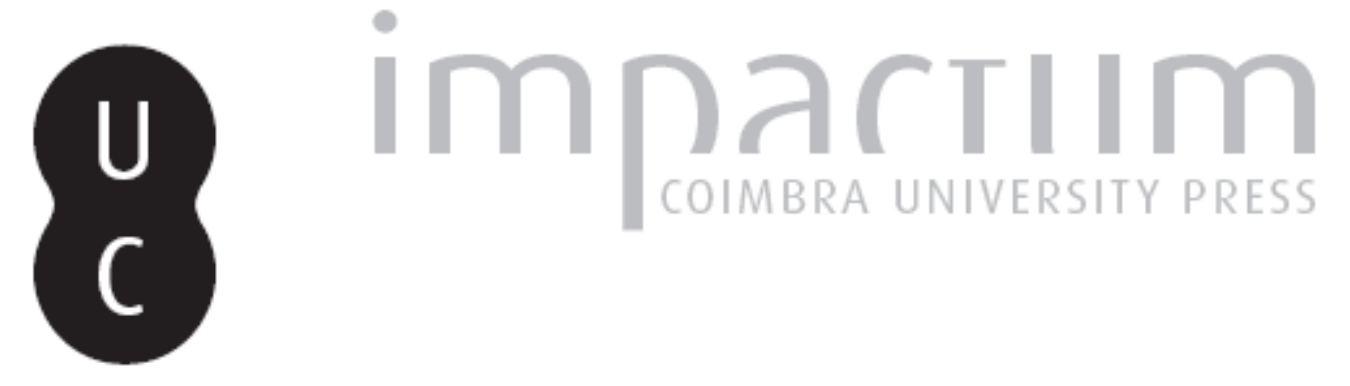

\title{
Dos legumes de vagem em Apício, De re coquinaria
}

Autor(es): $\quad$ Cândido, Guida da Silva

Publicado por: Imprensa da Universidade de Coimbra

URL persistente:

URI:http://hdl.handle.net/10316.2/37538

DOI:

DOI:http://dx.doi.org/10.14195/0872-2110_59_14

Accessed : $\quad$ 26-Apr-2023 01:14:20

A navegação consulta e descarregamento dos títulos inseridos nas Bibliotecas Digitais UC Digitalis, UC Pombalina e UC Impactum, pressupõem a aceitação plena e sem reservas dos Termos e Condições de Uso destas Bibliotecas Digitais, disponíveis em https://digitalis.uc.pt/pt-pt/termos.

Conforme exposto nos referidos Termos e Condições de Uso, o descarregamento de títulos de acesso restrito requer uma licença válida de autorização devendo o utilizador aceder ao(s) documento(s) a partir de um endereço de IP da instituição detentora da supramencionada licença.

Ao utilizador é apenas permitido o descarregamento para uso pessoal, pelo que o emprego do(s) título(s) descarregado(s) para outro fim, designadamente comercial, carece de autorização do respetivo autor ou editor da obra.

Na medida em que todas as obras da UC Digitalis se encontram protegidas pelo Código do Direito de Autor e Direitos Conexos e demais legislação aplicável, toda a cópia, parcial ou total, deste documento, nos casos em que é legalmente admitida, deverá conter ou fazer-se acompanhar por este aviso.

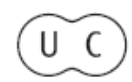


COIMBRA • 2014

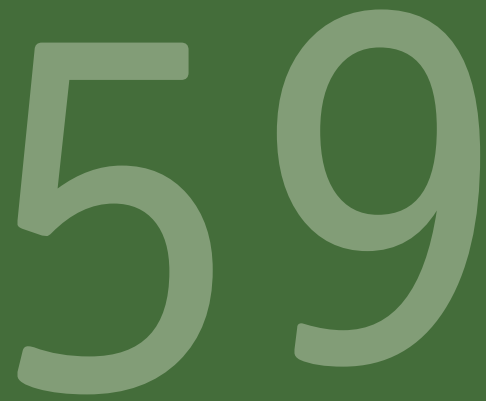

\title{
BOLETIM DE
}

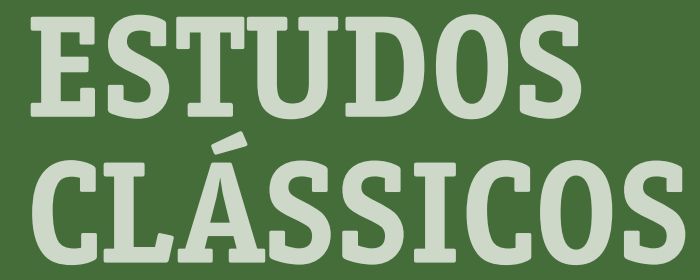

\author{
ASSOCIAÇÃO \\ PORTUGUESA \\ DE ESTUDOS \\ CLÁSSICOS \\ INSTITUTO \\ DE ESTUDOS \\ CLÁSSICOS
}




\title{
DOS LEGUMES DE VAGEM EM APÍCIO, DE RE COQUINARIA ${ }^{1}$
}

\section{ABOUT THE POD VEGETABLES IN APICIUS' DE RE COQUINARIA}

\author{
GUIDA DA SILVA CÂNDIDO \\ MESTRE EM ALIMENTAÇÃO: FONTES, CULTURA E SOCIEDADE. \\ INVESTIGADORA DO CECH DA FLUC NO PROJECTO DIAITA
}

Resumo: Este estudo procura abordar as diversas utilizações dos legumes de vagem no tratado De re coquinaria de Apicius. Após uma breve identificação do seu autor e de uma contextualização da incontornável obra da antiguidade clássica que é este trado de culinária, parte-se para uma abordagem específica ao Livro V, cuja temática são os legumes de vagem. Os Romanos cultivam uma multiplicidade de legumes ou leguminosas (legumina), isto é, os legumes de vagem, logo, com grãos. O comércio de legumes secos, torrados, inteiros, em pedaços, ou em farinha é praticado com muita intensidade. Identificam-se os alimentos, as técnicas e receitas. Finaliza-se com duas sugestões culinárias que representam um exercício de reconstituição arqueológica e de recriação.

Palavras-chave: De Re Coquinaria; Apício; Alimentação; Antiguidade Clássica; Património alimentar

Abstract: This study addresses the distinct uses of leguminous vegetables under the treaty De re coquinaria by Apicius. After a short

1 Trabalho elaborado no âmbito da unidade curricular Sabores do Passado: a Cozinha Grega e Romana, do Mestrado em Alimentação - Fontes, Cultura e Sociedade, da Faculdade de Letras da Universidade de Coimbra, lecionada pela Doutora Carmen Isabel Leal Soares. 
identification of the author and contextualization of this masterpiece in ancient classics, this paper focuses on Book $\mathrm{V}$, whose theme is leguminous vegetables. Ancient Romans used to plant a great variety of vegetables and legumes (legumina), i.e., leguminous vegetables, thus, vegetables with grains. Trade in vegetables, whether they were dried, toasted, whole, in pieces, or as vegetable flour, was extensive. This text identifies the ingredients, techniques and recipes. It ends by proposing two culinary suggestions, which represent an exercise of archaeological reconstitution and recreation. Keywords: De Re Coquinaria; Apicius; food; Classical Antiquity; food heritage

\section{APÍCIO - ESCRITOR? COZINHEIRO? EXCÊNTRICO?}

Tendo dispendido na cozinha cem milhões de sestércios e dissipado em cada um dos festins inúmeros côngios principescos e a enorme contribuição do Capitólio, pressionado pelas dívidas, viu-se então compelido a examinar pela primeira vez as suas contas; calculou restarem-lhe dez milhões e, como se assim ficasse reduzido a passar fome, pôs fim à vida envenenando-se ${ }^{2}$.

O relato não poderia ser mais esclarecedor em relação à personalidade de Marco Gávio Apício. Adverso, pouco lisonjeiro, criticável e cáustico.

Quem foi afinal este escritor, gastrónomo e cozinheiro? Qual a identidade de Apício? Nascido durante o reinado de Tibério, cerca de 25 a.C, Apício pertence à pequena aristocracia, filho de cavaleiro e amigo de membros da família imperial, graças à sua fortuna e fama.

Rodeado por uma pequena corte de jovens aristocratas - pretensos gastrófilos - que propõe iniciar na arte da culinária, um ócio prejudicial aos olhos de Séneca.

2 Séneca, Ad Heluiam, 10,8-9. 
As suas excentricidades culinárias chegaram até à atualidade. Inventar pratos com ingredientes inusitados como calcanhares de camelos, línguas de pavões, flamingos ou rouxinóis afiguram-se como ousadias que não deixam ninguém indiferente. Da mesma forma que a preparação de uma espécie de foie gras, engordando gansas com figos secos e matando-as com o excesso de vinho e mel para depois aproveitar os fígados, ou a preparação de garum ${ }^{3}$ confecionado com fígados de salmonetes, no qual mergulha posteriormente salmonetes vivos, são práticas que lhe conferem essa aura de extravagância inequívoca.

No entanto, se se atender às fontes, descobre-se que este dotado cozinheiro da antiguidade revela preocupações em tudo semelhantes aos grandes chefs da atualidade: a qualidade da matéria-prima, os ingredientes e as técnicas aplicadas no processo de confeção ${ }^{4}$. Apesar da dominante controvérsia à volta desta figura lendária, Apicius é um nome incontornável na História da Culinária e da Gastronomia, permanecendo como sinónimo de cozinheiro ou designação popular de glutão $0^{5}$.

\section{DE RE COQUINARIA - CONTEXTUALIZAÇÃO DA OBRA}

No momento em que Feuerbach proferiu a máxima "Diz-me o que comes, dir-te-ei quem és!" não estaria a referir-se à cozinha da antiguidade clássica nem tão pouco ao tratado de culinária de Apício, De re coquinaria. Contudo, essas sábias palavras poderiam ser aplicadas de uma forma transversal à história da alimentação.

3 O garum é um líquido ou milho culinário, preparado com pedaços de peixes de menor qualidade e vísceras dos mesmos, juntamente com ervas e deixados ao sol por um período de 1 a 3 meses em processo de fermentação.

4 Rodrigues 2010: 10-11.

5 Tertuliano, Apologia 3, 6. 
O Homem é o que come. E o que come é também aquilo que gostaria de ser. Ontem e hoje, a alimentação da humanidade poderá dividir-se em dois campos essenciais que se traduzem na necessidade e no prazer. E ambas as escolhas refletem hierarquias sociais e culturais, bem como as relações de poder ${ }^{6}$.

A juntar à escolha dos alimentos, aos básicos e aos supérfluos, surgem ainda as técnicas de preparação e confeção. Estes princípios constituem um elemento diferenciador ou unificador. A que se juntam ainda as questões da mesa e etiqueta; os rituais e normas; as interdições e uma gramática de saberes tão extensa quanto complexa.

A investigação acerca dos saberes e dos sabores do passado recorre com frequência aos tratados de culinária e gastronomia, nomeadamente aos livros de receitas. Dificilmente poderemos estabelecer comparação entre os atuais livros de culinária, profusamente ilustrados e rigorosamente descritos, e as fontes que nos chegam da antiguidade clássica e mesmo de épocas mais tardias como a Idade Média ou a Renascença, onde as informações relativas a quantidades e técnicas são limitadas ou negligenciadas.

De Re Coquinaria - a fonte visada nesta leitura e interpretação - é um compêndio de receitas de culinária da Antiga Roma, reunido por Marco Gávio Apício. Este conjunto de livros ou capítulos, compostos por Apício, foram, e continuam a ser, um sucesso que se concentra nas receitas e simultaneamente na personalidade excêntrica do seu autor.

A obra foi alvo de diversas alterações pelas mãos dos que a utilizavam, essencialmente os cozinheiros, verificando-se acréscimos e supressões. O formato atual, composto por dez livros, tem a sua origem no século IV da nossa era?.

Com receitas que denotam um claro gosto inusitado e remetem para o exótico, poder-se-á interpretar como um livro de gastronomia imperial

6 Esta análise é feita por diversos autores que se debruçam sobre a História da Alimentação, nomeadamente Castro 2012: 69.

7 Além dos dez livros iniciais, acresce o contributo de outro livro da autoria de Vinodário, como refere Rodrigues 2010: 14 . 
exclusiva da classe alta. Essa leitura será redutora se nos dispensarmos de analisar todos os ingredientes que compõem a obra e que apontam para receitas de gosto mais popular e do quotidiano. Desta forma, os seus utilizadores terão sido um grupo mais abrangente onde se encaixam personagens urbanas e cosmopolitas, com gostos transversais que englobam o exotismo mas também a frugalidade culinária.

Distante da sobriedade da cozinha equilibrada do siciliano Arquéstrato e com uma negação evidente do alimento cru, Apício combina o cozido e o assado, frequentemente por necessidade, em elaborações que neutralizam o sabor primário dos ingredientes.

A influência grega é manifestamente considerável, sublinhando uma troca entre culturas e salientando a passagem da cozinha romana de rústica a sofisticada. Posteriormente são detectáveis as analogias entre esta cozinha de Apício e o que irrompe na mesa da Europa medieval.

Em resumo, De re coquinaria reúne, nos seus dez livros, o gosto praticado por uma sociedade cosmopolita; a herança mediterrânea; a definição de práticas e sabores culinários.

As temáticas são variadas, um caminho que se faz desde as receitas elementares e económicas até às mais aprimoradas. Não descura ainda a inclusão de sugestões de conservação dos alimentos bem como receitas medicinais.

Cada livro é uma obra independente, que forma um todo coerente, mas que se individualiza pela organização temática. A saber: 0 cozinheiro aplicado; Picados; O hortelão; Receitas diversas; Legumes de vagem; Aves; 0 cozinheiro perdulário; Quadrúpedes; Mar e 0 pescador.

Analise-se o livro V-Legumes de Vagem.

\section{LEGUMES DE VAGEM | LIVRO V}

Os Romanos cultivam uma multiplicidade de legumes ou leguminosas (legumina), isto é, os legumes de vagem, logo, com grãos. O comércio de le- 
gumes secos, torrados, inteiros em pedaços, ou em farinha é praticado com muita intensidade. É esta a forma mais usual para a sua longa conservação.

- Das ervilhas (Pisum sativum, pisum)

Muito familiares na Roma antiga, são usualmente conservadas secas, condição em que se preservam por extensos períodos de tempo. São fervidas antes de se comerem. Se a cozedura se prolongar, transformam-se numa sopa suave ${ }^{8}$.

- Das favas (Vicia Faba, faba)

A fava é durante muito tempo a base da alimentação romana, cultivada de forma intensiva para servir a alimentação de todos, sobretudo dos mais desfavorecidos. A sua combinação com presunto é a matriz da alimentação dos pobres, dos trabalhadores braçais, dos camponeses e gladiadores. Em concreto, é o alimento de todos os que necessitam de robustez no seu quotidiano.

São comidas cruas, cozidas, fritas ou ainda transformadas em farinha (lomentum) para fazer pão?.

A variedade de favas é considerável. Contudo, a Fava de Baias cultivada na zona de Nápoles e mencionada por Apício, é a mais apreciada e de melhor categoria.

- Do grão-de-bico (Cicer, -eris, Cicer arientinum)

No mundo clássico, o grão-de-bico é servido como tragemata, sobremesa ${ }^{10}$. São comidos verdes; fritos; ou secos e depois cozidos. A sopa de grão-de-bico é comum e acessível como comida de rua na Roma antiga ${ }^{11}$.

8 Dalby 2003: 252.

9 André 1961: 35-37.

10 Os Romanos consumiam frequentemente estas leguminosas como sobremesa. Serão as "azevias" herdeiras desta prática? As "azevias" são um doce da cozinha tradicional portuguesa da região alentejana.

11 Dalby 2003: 84. 
- Do feijão-frade (Passiolus, fasiolus)

Introduzidos em Itália pela Grécia, são um dos raros exemplos em que os romanos não esperam o pleno desenvolvimento do fruto e desperdiçam reservas futuras para o inverno ${ }^{12}$.

\section{AS RECEITAS}

Em De re coquinaria, Apício, revela a cozinha que o distingue de outros gastrónomos e da simplicidade da cozinha mediterrânea. O trio 'pão, vinho e azeite', tão identitário da civilização clássica, não tem neste conjunto de livros uma representatividade predominante. Registados no grande conjunto de receitas, o vinho e o azeite têm papéis secundários. $O$ azeite, essencialmente como gordura, impondo-se a outras, nomeadamente a manteiga e a banha - conotadas com a cozinha dos povos bárbaros - expressa uma aplicação residual.

O vinho como condimento, também ele incorporado em grande número de receitas, não se prenuncia como elemento de destaque, antes como ingrediente de base.

A cozinha de Apício é uma cozinha de cheiros e aromas, de especiarias e ervas que se sobrepõem, que se anulam no excesso. É também uma cozinha com justaposição de várias proteínas, algumas bizarras, como os genitais femininos do gado porcino. o garum e o liquamen distinguem-se pela constante enunciação em receitas doces e salgadas. Atesta-se uma predisposição para o agridoce tão comum na cozinha asiática dos nossos dias.

- Com ervilhas e favas

Identificadas onze receitas com ervilhas, das quais cinco referentes a purés, a enumeração dos ingredientes pode fazer-se segundo uma

12 André 1961:39-40. 
distinção de categorias, aplicada a todas as outras receitas enunciadas no capítulo do Livro $V$.

As proteínas empregues são diversificadas e determinadas receitas chegam combinadas e sobrepostas, destacando-se as carnes, com uma representatividade reduzida de peixe. Neste caso, apenas sibas (sepia), uma espécie semelhante aos chocos, estão presentes na receita de Ervilhas índicas ${ }^{13}$.

Figuram os ovos, o leitão (porcellus), vulva de porca (uulua, ae), mioleiras (cerebellum), salsichas (farcimen, inis) da Lucânia, gordura de porco (omentum), presunto (petasio, onis), almôndegas (isicium), tordos (turdus), passarinhos (aucella) e frango (pullus).

Do rol de ervas aromáticas empregues neste receituário constam: coentro (coriandrum), lingústica (ligusticum), alcaravia (carui), aneto (anethum), manjericão (ocimus), orégão (origanum) e gengibre (gengiber, eris), as mais das vezes, acumuladas e não de uso individual. Acrescem as especiarias: cominho (comminum), pimenta (piper, eris) e pimenta branca (piper album). Componentes denominados molhos e condimentos são igualmente utilizados: o vinho (uinum), com algumas derivações (vinho branco - uinum candidum - e de passas - passum), o vinagre, o azeite (oleum), o mel (mel, mellis) e o insubstituível liquamen, presente na totalidade de receitas com ervilhas.

A referência a fruta ocorre isoladamente, na receita de Empadão de ervilhas, com a introdução de pinhão. Da mesma forma, os vegetais estão próximos da total ausência exceptuando a cebola (cepa), muito importante na cozinha greco-romana, e o alho-porro (porrum capitatum).

As receitas de favas perfazem um total de cinco. o puré de favas refere-se à sua utilização seca ou em farinha, designado conchicla ${ }^{14}$.

13 Índica, no original Indicum, refere-se à cor do prato após a sua confeção, devido à tinta da siba, semelhante ao choco, como refere Castro 1999: 143.

14 A farinha de favas secas, lomentum, é utilizada no puré e no fabrico do pão por ser bem tolerada pelo estômago. $O$ puré é usualmente acompanhado de presunto, como os demais pratos com favas. Idem: 145 . 
No que concerne às receitas de favas frescas de vagem, conhecidas por Favas de Baias, estas são aproveitadas de forma semelhante ao que atualmente se faz com o feijão verde.

A extensa lista de condimentos e ervas aromáticas é comparável às receitas com ervilhas. A saber: cominho, vinho, vinagre, liquamen, azeite, mel, mostarda (senapi, is), coentro, ligústica, arruda (ruta) e aipo (apium). $\mathrm{O}$ alho-porro é a única verdura incluída nas receitas.

Curiosamente, Apício indica receitas em que é facultativa a escolha entre as ervilhas e as favas. Sendo em número de quatro, duas são designadas à moda de Vitélio ${ }^{15}$.

Paralelamente às outras receitas, o uso de alho-porro, a malva (malva) - a ocorrer pela primeira e única vez - e a inclusão de diferentes ervas aromáticas, o funcho (feniculum), e a arruda, a que se junta novamente a ligústica, gengibre, aipo e coentro. Nas especiarias, surge apenas a referência à pimenta e aos mesmos ingredientes líquidos. As proteínas são vastas e variadas: ovos; almôndegas; salsichas de Lucânia. As vísceras ou miudezas como o fígado (iecur, -oris), mioleira e moelas (gizerium) e ainda os tordos e passarinhos são utilizados.

A técnica de cozer, utilizada na confeção das receitas com ervilhas, é dominante. Apresenta-se o processo de assar no Empadão de ervilhas ${ }^{16}$ e na receita Outro preparado de puré: puré com frango ou leitão $0^{17}$. Alude-se isoladamente ao processo de trinchar ${ }^{18}$.

Registe-se os utensílios referidos nas descrições culinárias: panela (caccabus); tabuleiro retangular (angular); almofariz (montarium); travessa (lanx, cis); vaso de Cumas (cumana); prato para puré (conchiclar); espeto (surculum) e terrina coberta (operculum).

15 Este imperador destacou-se pelas suas recreações gastronómicas. Poderá tratar-se de receitas por ele criadas ou então a ele dedicadas. Idem: 144.

16 “[...] Asse salsichas da Lucânia [...]”. Idem: 142.

17 "[...] unte o frango com gordura de porco, coloque-o numa terrina coberta, leve ao forno para cozinhar lentamente e sirva [...]”. Idem: 147.

18 “[...] frango trinchado [...]". Idem: 142. 
- Com grão-de-bico e feijão-frade

As receitas com ambas as leguminosas encontram-se agrupadas na categoria das mais elementares. Nas quatro sugestões enunciadas, a lista de ingredientes é curta e sem os excessos praticados noutras receitas. A única erva aromática incorporada é o funcho fresco. Acrescente-se os cominhos no campo dos condimentos, garum de vinho (oenagarum), pimenta, sal (sal, salis), liquamen e o azeite. Inserem-se como proteína os ovos.

As técnicas referidas na preparação das sugestões com grão-de-bico e feijão-frade incluem cozer e fritar. Permanece a ausência de referência a quantidades de ingredientes, tempos de preparação e temperaturas nos processos.

\section{DA TEORIA À PRÁTICA}

O mestrado em Alimentação: Fontes Cultura e Sociedade permite reunir competências que visam a compreensão da temática da alimentação através da sua evolução ao longo da história, bem como as diversas abordagens a este domínio, contextualizando o seu papel no foro do património cultural. A caracterização da Cultura Alimentar nas diferentes épocas da história da Humanidade, fundada no estudo das fontes orais, escritas e iconográficas, possibilita a reconstituição de receituários de outros tempos. Constata-se que esses contributos de gostos e hábitos gastronómicos de um passado remoto, contribuem para o perfil da cozinha contemporânea, possibilitando o exercício de interpretar de forma linear as receitas ou, através dos produtos e técnicas indicados, recriar sugestões culinárias idênticas ao passado, mas adequadas aos palatos de hoje.As receitas agora apresentadas correspondem a duas interpretações distintas. A primeira procura seguir com rigor as diretrizes do receituário de Apício, mantendo os ingredientes e as técnicas.

Na segunda, uma livre interpretação de uma receita com favas pretende experienciar uma sugestão que incorpora ingredientes comuns às 
receitas de legumes do tratado De re coquinaria, desconstruindo mas fazendo uso de técnicas, utensílios e princípios exequíveis à época do tratado.

- Interpretação de uma receita com ervilhas $(\mathrm{V}, 3,4 ; 189)^{19}$

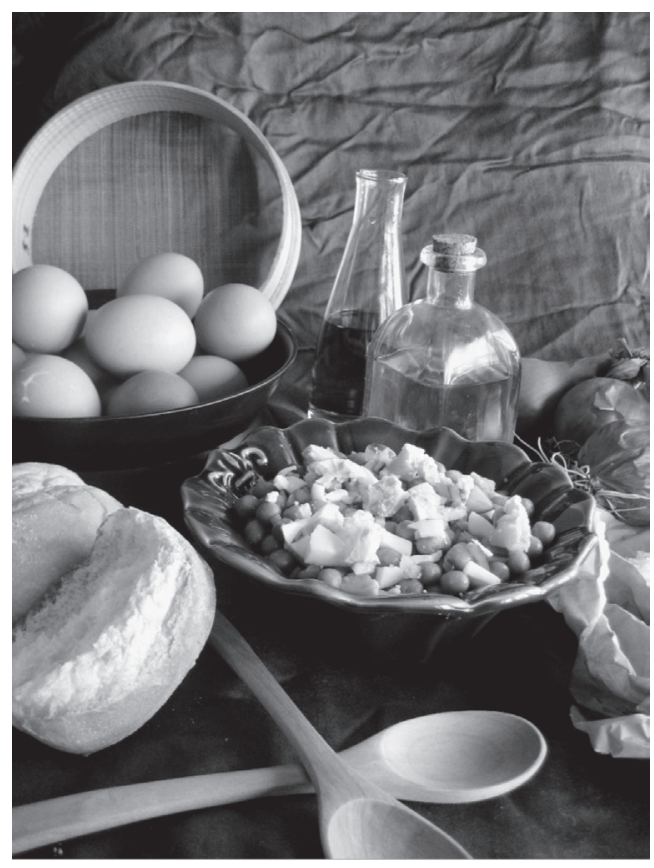

$200 \mathrm{~g}$ de ervilhas descascadas

$1 / 4$ de cebola picada

2 ovos cozidos

Azeite q.b.

Vinagre q.b.

Sal q.b.

19 Idem: 143, 144.

Receita executada pela autora e publicada no blog Panela sem (de)pressão em 2 de janeiro de 2013. http://panelasemdepressao.wordpress.com/2013/01/02/de-re-coquinaria-apicius/ 
Cozem-se as ervilhas em água. Escorrem-se e colocam-se em água fria para travar o processo de cozedura. Voltam a escorrer-se. Colocam-se numa taça. Junta-se a cebola picada e tempera-se com azeite, sal e vinagre. Picam-se os ovos cozidos e envolve-se no preparado de ervilhas, retificando o azeite.
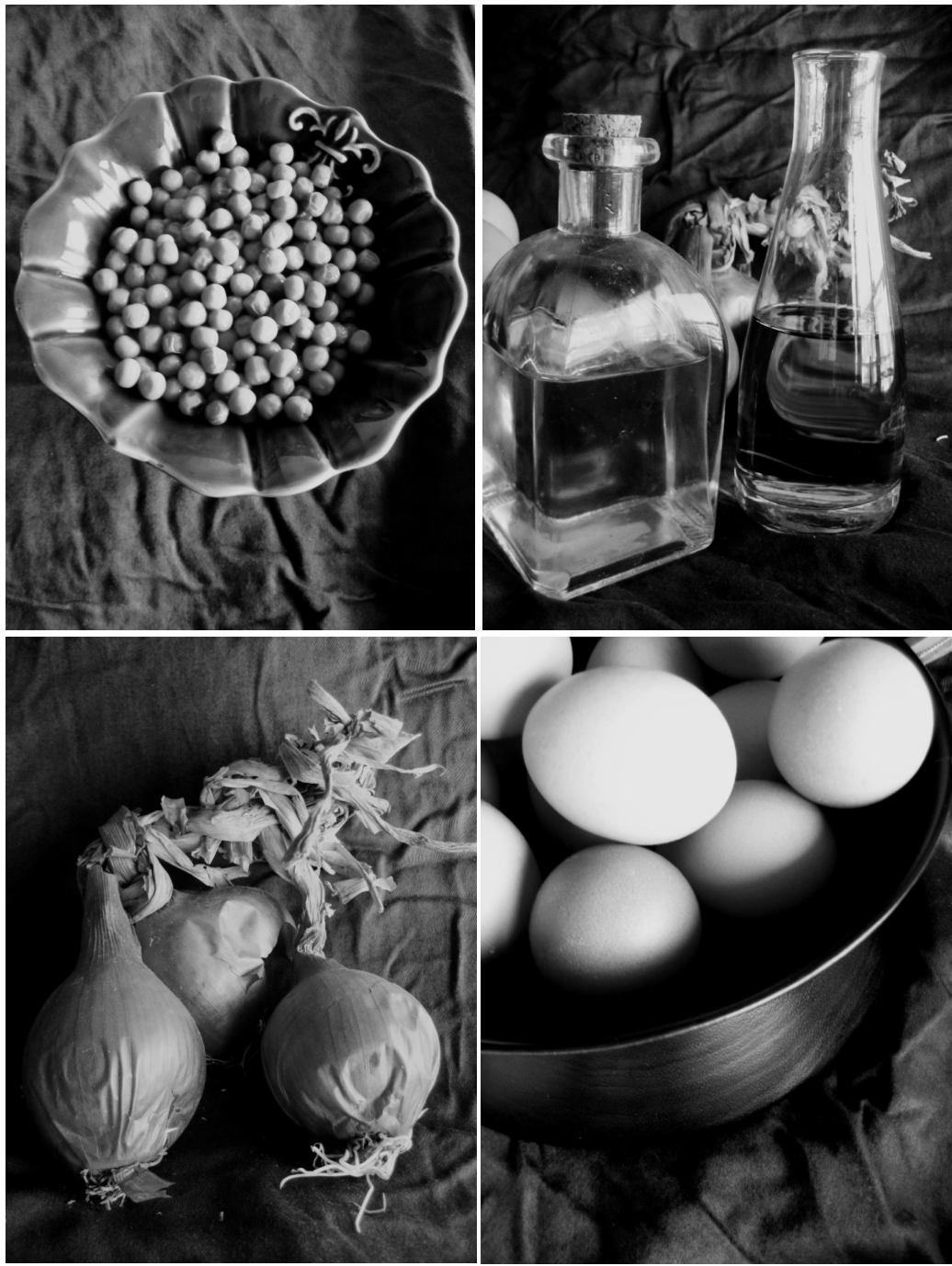
- Livre interpretação de uma receita com favas

Pasta de favas com ervas aromáticas ${ }^{20}$

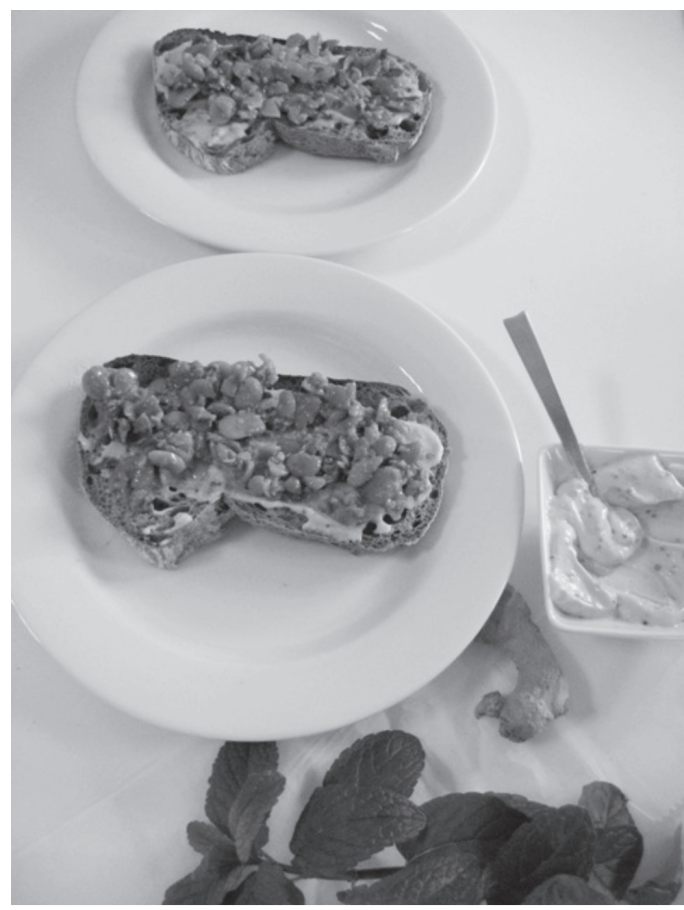

$200 \mathrm{~g}$ de favas descascadas

2 dentes de alho

Folhinhas de hortelã

2 colheres de chá de coentros em pó

Flor de sal a gosto

Pimenta moída

Azeite a gosto

Mostarda

Fatias de pão torrado

20 Receita executada pela autora e publicada no blog Panela sem (de)pressão em 1 de maio de 2012. http://panelasemdepressao.wordpress.com/2012/05/01/de-maio-sao-as-favas-2/ 
Cozem-se as favas em água e sal até ficarem tenras, cerca de 7 minutos. Escorrem-se e passam-se por água fria, para manter a cor. Descascam-se as favas. Numa taça juntam-se com azeite a gosto, os alhos ralados, o gengibre igualmente ralado e os coentros em pó.

Tempera-se com sal e pimenta. Apesar das favas terem sido temperadas na cozedura, talvez precisem de mais um pouco de sal depois de misturadas com os restantes ingredientes.

Pisa-se tudo num almofariz, de forma a ficar com pedaços inteiros de favas. Barram-se as fatias de pão torrado com uma fina camada de mostarda e espalha-se a mistura temperada de favas.
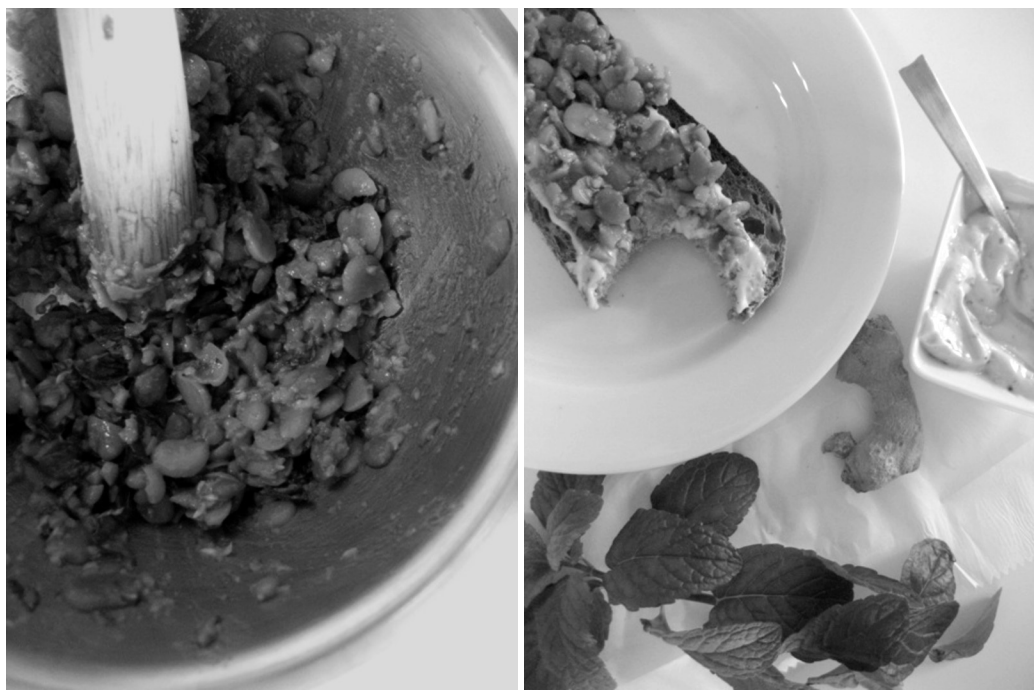

\section{BIBLIOGRAFIA}

Castro, Inês de Ornellas (1999), O livro de Cozinha de Apício. Um breviário do gosto imperial romano. Collares. Sintra.

Aguilera, C. (2001), História da Alimentação Mediterrânica. Terramar. Lisboa. André, J. (1961), L'alimentation et la cuisine a Roma. Paris. C. Klincksieck. 
Castro, I. O. (2012), “Discursos e Rituais na Mesa Romana: Luxo, Moralismo e Equívocos", in Contributos para a História da Alimentação na Antiguidade, C. Soares e P. B. Dias (coords.), Centro de Estudos Clássicos e Humanísticos. Universidade de Coimbra. Coimbra: 69 - 79.

Dalby, A. (2003), Food in the Ancient World. From A to Z. London and New York.

Flandrin, J. l. et Montanari, M. (2008), História da alimentação, (coords). por J.-L. Flandrin et M. Montanari, vol. I, "Dos primórdios à Idade Média". Terramar. Lisboa.

Apício, De Re Coquinaria I - III: introdução, tradução e notas. (2010) Rodrigues, A. P. trad. Universidade Federal do Rio Grande do Sul. Porto Alegre. 